\title{
Rhinitis medicamentosa
}

\author{
Lok-Yee Joyce Li, ${ }^{1,2}$ Shin-Yi Wang, ${ }^{3}$ Cheng-Yu Tsai, ${ }^{4}$ Cheng-Jung Wu (i) 2,5,6
}

'Department of Medicine, Shin Kong Wu Ho Su Memorial Hospital, Taipei, Taiwan ${ }^{2}$ Department of Otolaryngology, School of Medicine, College of Medicine, Taipei Medical University, Taipei, Taiwan ${ }^{3}$ Department of Nursing, National Taiwan University Hospital, Hsin-Chu Branch, Hsinchu, Taiwan

${ }^{4}$ Department of Civil and Environmental Engineering, Imperial College London, London, UK

${ }^{5}$ Department of Otolaryngology, Shuang Ho Hospital Ministry of Health and Welfare, Taipei Medical University, New Taipei City, Taiwan

${ }^{6} \mathrm{PhD}$ Degree Program of Biomedical Science and Engineering, National Yang Ming Chiao Tung University, Hsinchu, Taiwan

\section{Correspondence to} Dr Cheng-Jung Wu; B101090126@tmu.edu.tw

Accepted 11 October 2021

\section{DESCRIPTION}

A 34-year-old male with a history of allergic rhinitis presented with nasal obstruction for 2 months. According to him, he is allergic to the most common indoor allergens such as dust mites, cat and dog dander. The main symptoms were associated with difficulty in nasal breathing. $\mathrm{He}$ also suffered from other minor associated symptoms such as rhinorrhoea, postnasal drip, palatial itch and throat itch. Two months prior to presentation, he suffered from rhinorrhoea and was prescribed topical decongestant nasal spray. Physical examination revealed inferior turbinate hypertrophy with crust formation (figure 1). This symptom of nasal obstruction typically resolved 3-5 days after the use of intranasal decongestants. However, the patient increased both the dose and the frequency of the application of nasal sprays in the hope of relieving the symptoms, which in turn worsened the situation. Rhinitis medicamentosa is a condition characterised by nasal congestion triggered by the extensive use of intranasal decongestants. ${ }^{12}$ As the patient was not on any concomitant antihypertensives, nonsteroidal anti-inflammatory drugs or cocaine, immediate cessation of the use of topical nasal decongestants was suggested. One day after cessation of the topical nasal decongestants, rhinoendoscopy showed rebound congestion of the inferior turbinate. The patient initiated immunotherapy and medication with antihistamines and topical steroid nasal spray. The patient reported alleviation of both rhinorrhoea and difficulty in nasal

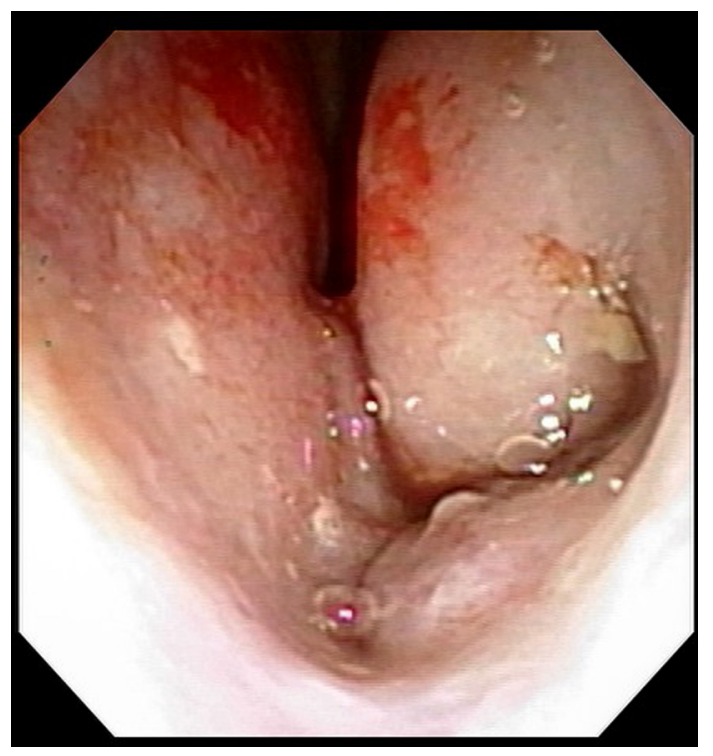

Figure 1 Physical examination revealed inferior turbinate hypertrophy with crust formation.

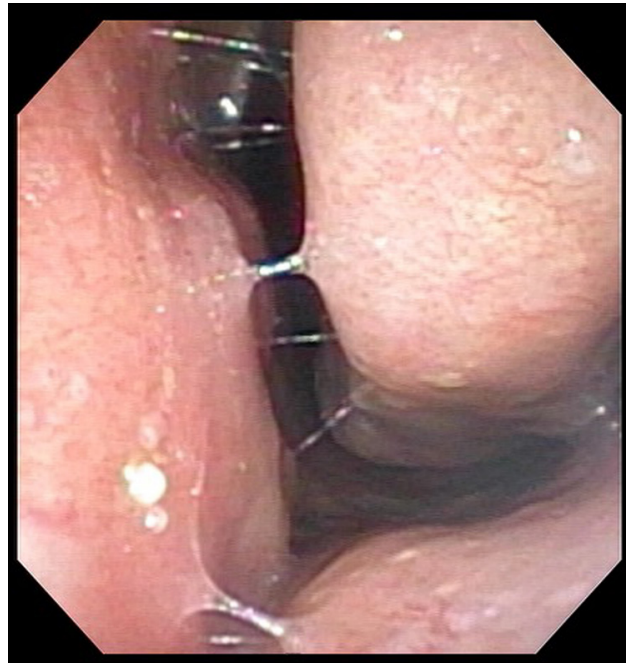

Figure 2 Physical examination revealed alleviation of both rhinorrhoea and difficulty in nasal breathing after 3 months.

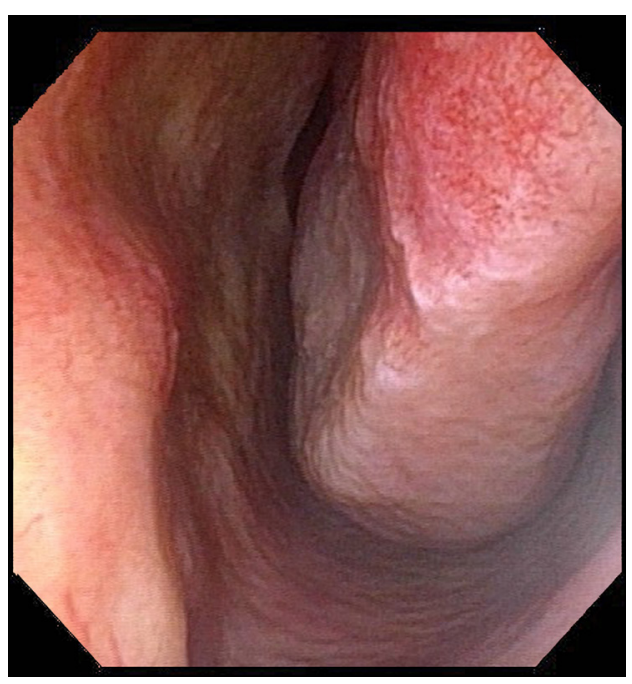

Figure 3 Rhinoendoscopy 1 month after operation showed increased volume of inferior nasal meatus.

\section{Learning points}

- Rhinitis medicamentosa is a drug-induced and non-allergic form of rhinitis.

- Rhinitis medicamentosa is associated with prolonged use of topical vasoconstrictors, for example, local decongestants.

- Over-the-counter topical decongestants have a general warning that they should be discontinued after 3 days of use. 
breathing after 3 months (figure 2). However, the patient still complained of nasal obstruction at sleep. Thus, inferior turbinate reduction operation was done. Follow-up rhinoendoscopy 1 month after operation showed increased volume of inferior nasal meatus (figure 3). The patient has become asymptomatic with no recurrent nasal obstruction.

Contributors C-JW and L-YJL performed the experiments. L-YJL, S-YW and C-YT contributed reagents/materials/analysis tools. L-YJL wrote the paper.

Funding The authors have not declared a specific grant for this research from any funding agency in the public, commercial or not-for-profit sectors.
Competing interests None declared.

Patient consent for publication Consent obtained directly from patient(s)

Provenance and peer review Not commissioned; externally peer reviewed.

\section{ORCID iD}

Cheng-Jung Wu http://orcid.org/0000-0002-7443-2119

\section{REFERENCES}

1 Wahid NWB, Shermetaro C. Rhinitis medicamentosa. Treasure Island (FL): StatPearls Publishing, 2021.

2 Zucker SM, Barton BM, McCoul ED. Management of rhinitis medicamentosa: a systematic review. Otolaryngol Head Neck Surg 2019;160:429-38.

Copyright 2021 BMJ Publishing Group. All rights reserved. For permission to reuse any of this content visit https://www.bmj.com/company/products-services/rights-and-licensing/permissions/

BMJ Case Report Fellows may re-use this article for personal use and teaching without any further permission.

Become a Fellow of BMJ Case Reports today and you can:

- Submit as many cases as you like

- Enjoy fast sympathetic peer review and rapid publication of accepted articles

- Access all the published articles

- Re-use any of the published material for personal use and teaching without further permission

Customer Service

If you have any further queries about your subscription, please contact our customer services team on +44 (0) 2071111105 or via email at support@bmj.com.

Visit casereports.bmj.com for more articles like this and to become a Fellow 